\title{
Ceftazidime-avibactam: an evidence-based review of its pharmacology and potential use in the treatment of Gram-negative bacterial infections
}

This article was published in the following Dove Press journal:

Core Evidence

24 January 2014

Number of times this article has been viewed

\author{
Philippe Lagacé-Wiens ${ }^{1,2}$ \\ Andrew Walkty ${ }^{1,2}$ \\ James A Karlowsky ${ }^{1,2}$ \\ 'Clinical Microbiology, Diagnostic \\ Services Manitoba, ${ }^{2}$ Department of \\ Medical Microbiology and Infectious \\ Diseases, Faculty of Medicine, \\ University of Manitoba, Winnipeg, \\ MB, Canada
}

Correspondence: Philippe Lagacé-Wiens Saint-Boniface Hospital, L4025-409 Taché Avenue, Winnipeg, MB R2H 2A6, Canada $\mathrm{Tel}+\mathrm{I} 2042372483$

Fax + I 2042377678

Email plagacewiens@dsmanitoba.ca

\begin{abstract}
Avibactam (NXL104, AVE1330A) is a semi-synthetic, non- $\beta$-lactam, $\beta$-lactamase inhibitor that is active against Ambler class $A$, class $C$, and some class $D$ serine $\beta$-lactamases. In this review, we summarize the in vitro data, pharmacology, mechanisms of action and resistance, and clinical trial data relating to the use of this agent combined with ceftazidime for the treatment of Gram-negative bacterial infections. The addition of avibactam to ceftazidime improves its in vitro activity against Enterobacteriaceae and Pseudomonas aeruginosa. Avibactam does not improve the activity of ceftazidime against Acinetobacter spp., Burkholderia spp., or most anaerobic Gram-negative rods. Pharmacodynamic data indicate that ceftazidime-avibactam is bactericidal at concentrations achievable in human serum. Animal studies demonstrate that ceftazidime-avibactam is effective in ceftazidime-resistant Gram-negative septicemia, meningitis, pyelonephritis, and pneumonia. Limited clinical trials published to date have reported that ceftazidime-avibactam is as effective as therapy with a carbapenem in complicated urinary tract infection and complicated intra-abdominal infection (combined with metronidazole) including infection caused by cephalosporin-resistant Gram-negative isolates. Safety and tolerability of ceftazidime-avibactam in clinical trials has been excellent, with few serious drug-related adverse events reported. Given the abundant clinical experience with ceftazidime and the significant improvement that avibactam provides in its activity against contemporary $\beta$-lactamaseproducing Gram-negative pathogens, it is likely this new combination agent will play a role in the empiric treatment of complicated urinary tract infections (monotherapy) and complicated intra-abdominal infections (in combination with metronidazole) caused or suspected to be caused by antimicrobial-resistant pathogens (eg, extended spectrum beta-lactamase-, AmpCor Klebsiella pneumoniae carbapenemase-producing Enterobacteriaceae and multidrug-resistant $P$. aeruginosa). Potential future uses also include hospital-acquired pneumonia (in combination with antistaphylococcal and antipneumococcal agents) or treatment of skin and soft tissue infections caused by antimicrobial-resistant Gram-negative pathogens (eg, diabetic foot infections), but further clinical trials are required.
\end{abstract}

Keywords: $\beta$-lactamase, microbiology, pharmacokinetics, NXL-104, clinical trials, review

Core evidence clinical impact summary

\begin{tabular}{lll}
$\begin{array}{l}\text { Outcome } \\
\text { measure }\end{array}$ & Evidence & Implications \\
\hline In vitro activity & Ceftazidime-avibactam is active against most \\
studies & Gram-negative Enterobacteriaceae, including \\
& multidrug-resistant isolates, and has significant \\
& activity against Pseudomonas aeruginosa. Activity is \\
& limited against Gram-negative anaerobes.
\end{tabular}

(Continued) 


\begin{tabular}{|c|c|c|}
\hline $\begin{array}{l}\text { (Continued) } \\
\text { Outcome } \\
\text { measure }\end{array}$ & Evidence & Implications \\
\hline $\begin{array}{l}\text { Disease-oriented } \\
\text { evidence }\end{array}$ & Animal models & $\begin{array}{l}\text { Ceftazidime-avibactam is likely safe and effective for } \\
\text { the treatment of clAl and cUTI. Treatment of clAl } \\
\text { will require combination therapy with metronidazole } \\
\text { or another anti-anaerobic antimicrobial agent. } \\
\text { Effective for the treatment of resistant Gram- } \\
\text { negative bacteremia, meningitis, pneumonia, } \\
\text { pyelonephritis, and thigh infections. }\end{array}$ \\
\hline $\begin{array}{l}\text { Patient-oriented } \\
\text { evidence }\end{array}$ & $\begin{array}{l}\text { Clinical trials in } \\
\text { hospitalized patients } \\
\text { with clAls and cUTls }\end{array}$ & $\begin{array}{l}\text { When available, ceftazidime-avibactam will likely be } \\
\text { an option for the treatment of hospitalized patients } \\
\text { with cIAI (with metronidazole) and cUTI. }\end{array}$ \\
\hline $\begin{array}{l}\text { Economic } \\
\text { evidence }\end{array}$ & None currently & \\
\hline
\end{tabular}

\section{Introduction}

Cephalosporins remain important agents in the treatment of many types of bacterial infections because of their broad-spectrum activity, well-characterized pharmacokinetic and pharmacodynamic properties, and proven safety and efficacy. ${ }^{1}$ Ceftazidime is a third-generation cephalosporin that was introduced into clinical use in the 1980s because it demonstrated broad-spectrum activity against Gram-positive cocci and Gram-negative bacilli, including Pseudomonas aeruginosa. Unfortunately, over time, the utility of all cephalosporins to treat infections involving Gram-negative bacilli is known to have become compromised by increasingly present extended-spectrum $\beta$-lactamases (ESBLs), ${ }^{2}$ Klebsiella pneumoniae carbapenemases (KPCs), ${ }^{3}$ metallo- $\beta$-lactamases, ${ }^{3}$ and chromosomal AmpC $\beta$-lactamases, ${ }^{4}$ as well as multidrug-resistant phenotypes. ${ }^{5}$ Recent surveillance data from Europe and the United States indicates that $<75 \%$ of nosocomial isolates of P. aeruginosa and Klebsiella spp. are now susceptible to ceftazidime. ${ }^{6}$ Further, resistance to ceftazidime in Escherichia coli isolates from intra-abdominal infections and urinary tract infections currently exceeds $10 \%$ in many North American hospitals..$^{6-8}$

Avibactam (NXL104, AVE1330A) was first reported in 2003 and is a non- $\beta$-lactam (diazabicyclooctane), $\beta$-lactamase inhibitor that is active against known Ambler class $A$ and $C \beta$-lactamases and which also possesses activity against some Ambler class D enzymes. ${ }^{9}{ }^{10}$ Avibactam is being developed in combination with ceftazidime, as well as in combination with ceftaroline, with the intention of inhibiting $\beta$-lactamases with activity against these cephalosporins and therefore broadening their spectra of activity. Ceftazidimeavibactam is currently in Phase III clinical trials for treatment of complicated urinary tract infection and complicated intra-abdominal infection (http://clinicaltrials.gov, identifiers
NCT01595438, ${ }^{11}$ NCT01599806, ${ }^{12}$ NCT01499290, ${ }^{13}$ and NCT01500239 $9^{14}$ ).

This article will review the existing published data for ceftazidime-avibactam, including chemistry, microbiology, mechanisms of action, mechanisms of resistance, pharmacokinetics and pharmacodynamics, clinical trials, and safety. Literature for this review was obtained via a comprehensive search of MEDLINE, Scopus, and databases of scientific meetings from 2005 to September 2013 for all materials containing the terms "ceftazidime" and any containing "avibactam," "NXL104," or "AVE1330A."

\section{Chemistry}

The chemical structure of ceftazidime is $(6 R, 7 R, Z)-7-(2-$ (2-aminothiazol-4-yl)-2-(2-carboxypropan-2-yloxyimino) acetamido)-8-oxo-3-(pyridinium-1-ylmethyl)-5-thia-1-azabicyclo[4.2.0] oct-2-ene-2-carboxylate (molecular formula, $\mathrm{C}_{22} \mathrm{H}_{22} \mathrm{~N}_{6} \mathrm{O}_{7} \mathrm{~S}_{2}$; molecular mass, $546.58 \mathrm{~g} / \mathrm{mol}$ ) (Figure 1). Ceftazidime, like other cephalosporins and cephamycins, contains a cephem nucleus (a bicyclic ring system composed

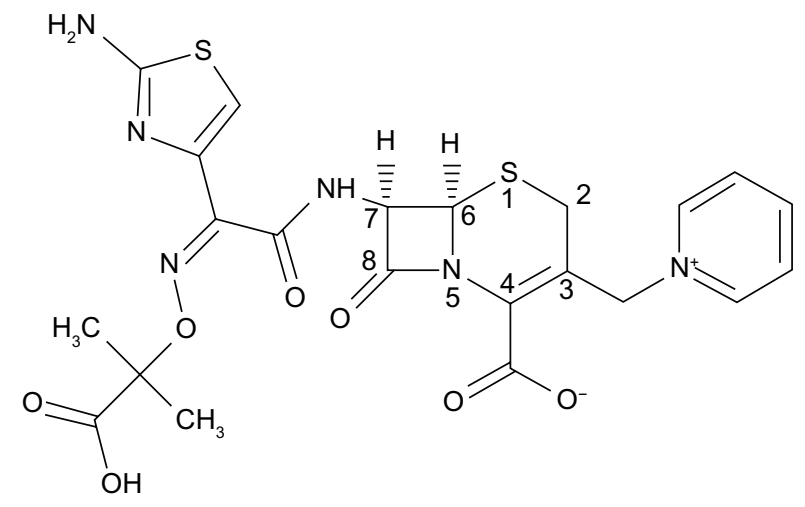

Figure I Chemical structure of ceftazidime. 
of a four-member $\beta$-lactam ring fused with a six-member dihydrothiazine ring, with a sulfur atom at position 1 , a double bond at position 3, and a carboxylic acid at position 4). ${ }^{1,15}$ The characteristic properties of specific cephalosporins arise from side-chains attached to the cephem nucleus at positions 3 and 7 and have been extensively reviewed elsewhere. ${ }^{16-18} \mathrm{At}$ position 3, ceftazidime has a methylpyridinium group that is responsible for its activity against $P$. aeruginos ${ }^{16}$ and provides enhanced water solubility because of its zwitterionic properties. ${ }^{15}$ At position 7 , ceftazidime has an aminoacyl group with an aminothiadiazole ring and a carboxypropyloxyimino chain linked to its $\alpha$-carbon. An aminothiadiazole ring is frequently found in extended-spectrum cephalosporins because it confers increased activity against Gram-negative bacilli. The carboxypropyl-oxyimino group confers significantly increased activity against $P$. aeruginosa and slightly less activity against Enterobacteriaceae compared with the methoxyimino group frequently found in other thirdgeneration cephalosporins; both the carboxypropyl-oxyimino group and the methoxyimino group confer similar stability to $\beta$-lactamases. ${ }^{19}$ Ceftazidime is synthesized in a multistep process using 7-aminocephalosporanic acid as starting material; it is available for human use in an anhydrous form or as a pentahydrate salt and is stable at room temperature for 24 hours or for 7 days at $4^{\circ} \mathrm{C}$ following reconstitution.

The chemical structure of avibactam is trans-7-oxo6-(sulfoxy)-1,6-diazabicyclo[3.2.1] octan-2-carboxamide (molecular formula, $\mathrm{C}_{7} \mathrm{H}_{10} \mathrm{~N}_{3} \mathrm{O}_{6} \mathrm{~S}$; molecular mass, $265.25 \mathrm{~g} / \mathrm{mol}$ ) (Figure 2). ${ }^{9}$ Avibactam is not a $\beta$-lactam; however, it closely resembles $\beta$-lactams in key areas. The carbonyl at position 7 of avibactam mimics the $\beta$-lactam carbonyl of a cephalosporin such as ceftazidime. Similarly, the sulfate

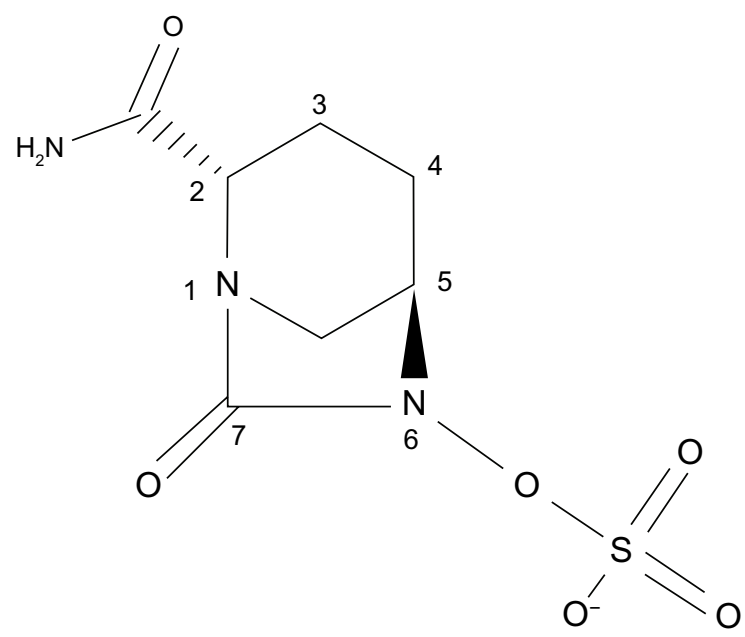

Figure 2 Chemical structure of avibactam. at position 6 of avibactam resembles the carboxyl group at ceftazidime position 4 , and the carboxamide at position 2 of avibactam aligns with the aminoacyl side-chain of ceftazidime at position 7 . The sulfate group is the only ionizable moiety on avibactam. Avibactam is semisynthetic and is produced via a nine-step enantio-selective process. ${ }^{9,20}$ Avibactam is synthesized as a sodium salt that is water soluble and stable in aqueous solution at room temperature. ${ }^{21}$ Avibactam has been dosed in humans at a ratio of 1:4 in combination with ceftazidime.

\section{Microbiology}

The in vitro activity of ceftazidime-avibactam has been evaluated against a wide range of organisms in numerous settings. ${ }^{22-34}$ Minimum inhibitory concentration (MIC) ${ }_{50}$, $\mathrm{MIC}_{90}$, and $\mathrm{MIC}$ ranges for Gram-negative pathogens are presented in Table 1. The most common method of testing has been broth microdilution with $4 \mu \mathrm{g} / \mathrm{mL}$ fixed concentration of avibactam and varying, often doubling dilution, concentrations

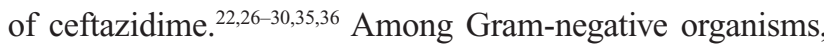
$\mathrm{MIC}_{50}$ and $\mathrm{MIC}_{90}$ values are low for all Enterobacteriaceae, including most ceftazidime-resistant isolates (Table 1). Assuming a breakpoint of $4 \mu \mathrm{g} / \mathrm{mL}$ (the Clinical and Laboratory Standards Institute [CLSI] Enterobacteriaceae breakpoint for ceftazidime), nearly all isolates of Enterobacteriaceae would be considered susceptible. Ceftazidime-avibactam is highly active against Haemophilus spp., Moraxella spp., and Neisseria spp., but offers no significant improvement over ceftazidime alone (Lagacé-Wiens P, unpublished data, 2012). This is not surprising, given the lack of $\beta$-lactamases active against ceftazidime in these organisms. Although ceftazidime resistance in these species is extremely rare at this time, it is mediated by alterations in penicillin-binding proteins (PBPs) and avibactam is not expected to offer significant improvement in $\mathrm{MIC}_{50}$ and $\mathrm{MIC}_{90}$ values for these resistant isolates. The activity of ceftazidimeavibactam against the nonfermenting Gram-negative rods is variable. ${ }^{28,30,32}$ Ceftazidime's $\mathrm{MIC}_{50}$ and $\mathrm{MIC}_{90}$ are reduced for $P$. aeruginosa by the addition of avibactam, ostensibly due to the inactivation of the AmpC (class C) $\beta$-lactamases present in these isolates; however, the available data suggest that avibactam does not restore the activity of ceftazidime against $P$. aeruginosa as reliably as it does for Enterobacteriaceae, likely due to the presence of additional mechanisms of resistance (porin alterations, efflux, metallo- $\beta$-lactamases, or OXA $\beta$-lactamases). ${ }^{29}$ The activity of ceftazidime-avibactam against Acinetobacter baumannii is no better than that of ceftazidime alone. ${ }^{28,30}$ This is likely due to the common presence 


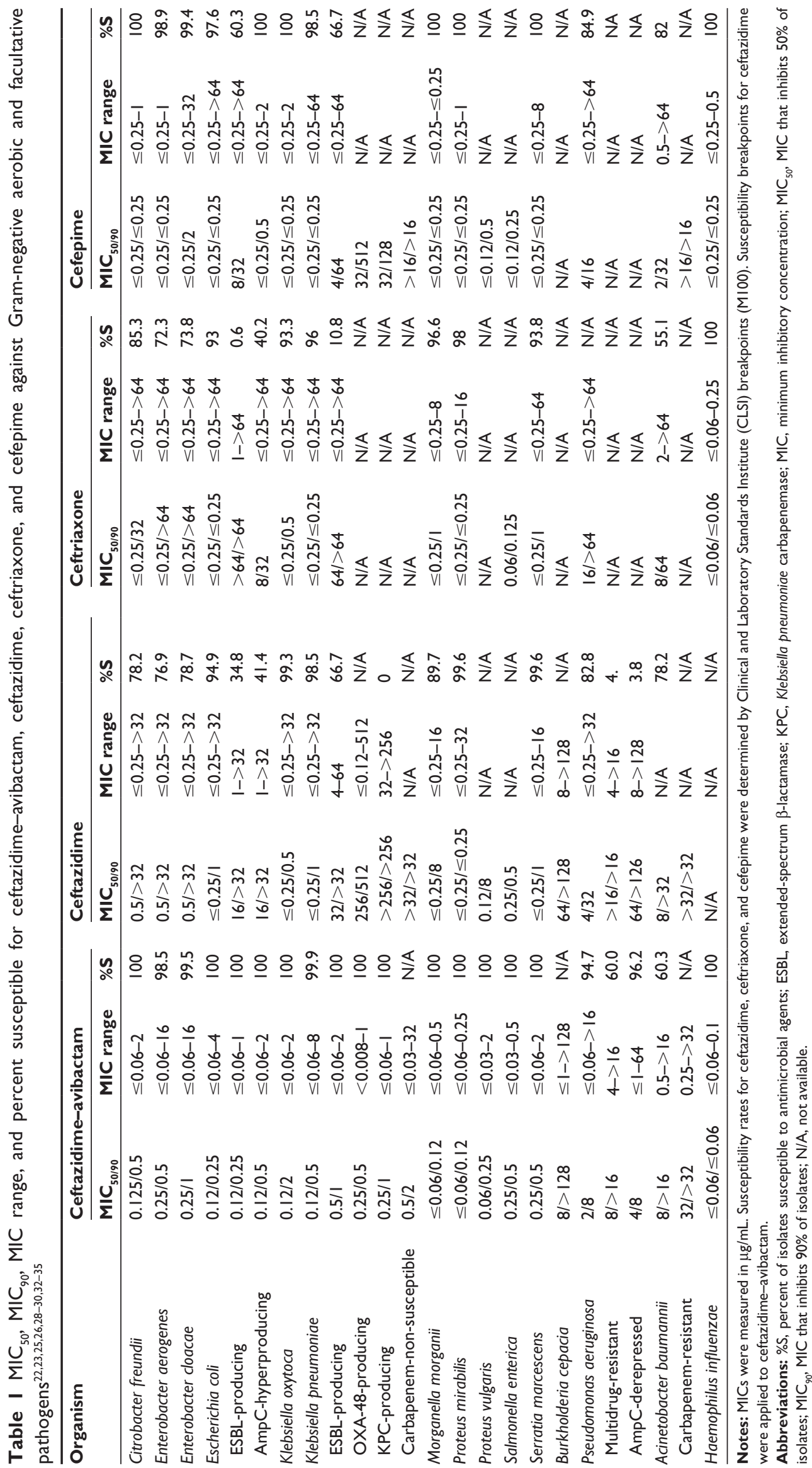


of OXA $\beta$-lactamases that are not inhibited by avibactam in Acinetobacter spp.. Avibactam does not appreciably reduce the MIC of ceftazidime for Burkholderia cepacia. ${ }^{28,30}$ Although the exact reason for the lack of synergism between ceftazidime and avibactam for B. cepacia remains unclear, it is likely that non$\beta$-lactamase-mediated resistance to cephalosporins, in the form of reduced permeability (outer membrane porin alterations), efflux pumps, and altered PBPs, plays a greater role than betalactamases in the development of cephalosporin-resistance in this species. ${ }^{37}$ Ceftazidime-avibactam is not active against Stenotrophomonas spp. (Lagacé-Wiens P, unpublished data, 2012), due to the universal presence of metallo- $\beta$-lactamases in these species.

Among Gram-negative anaerobes, ceftazidime-avibactam has limited activity (Table 2). MICs are noted to be elevated for most Bacteroides spp., and the combination would not be expected to be clinically effective..$^{27,38}$ Avibactam does, however, reduce the MIC of ceftazidime for Prevotella and Porphyromonas spp., and may be clinically effective where these pathogens are likely to be encountered. ${ }^{27,38}$

\section{Mechanism of action}

The mechanism of action of ceftazidime is well established and has been described elsewhere. ${ }^{39}$ Briefly, like all $\beta$-lactam antimicrobial agents, ceftazidime binds to a variety of PBPs. The binding affinity of various cephalosporins to the PBPs of Gram-negative organisms varies by cephalosporin, and the chemical structure of ceftazidime is such that it is primarily an inhibitor of PBP3 of Gram-negative bacteria, including P. aeruginosa. Binding of cephalosporins to PBPs results in the inhibition of cell wall synthesis. Ultimately, cell death occurs through mechanisms that are incompletely understood.

Avibactam is a non- $\beta$-lactam inhibitor of $\beta$-lactamases. ${ }^{40}$ $\beta$-lactamases are a highly diverse group of enzymes, found in a wide variety of bacteria, which confer varying degrees of resistance to $\beta$-lactam antimicrobial agents. ${ }^{41}$ The spectrum of activity and mechanism of these enzymes vary by type and subtype, and a wide variety have been described.$^{41}$ New $\beta$-lactamases are continuously being reported and there is a recognized phenomenon of evolution in these enzymes, often observed in response to the introduction of new antimicrobial agents. Several $\beta$-lactamase classification schemes have been described, but the most commonly used are the Ambler molecular scheme, based on the amino acid and subsequent structural similarity between enzymes and the Bush-JacobyMedeiros classification, based on the functionality or activity of the enzymes on different $\beta$-lactam antimicrobial agents. ${ }^{41}$ Since the molecular structure of the $\beta$-lactamases is the primary determinant of inhibitor activity, the Ambler classification will be the focus of this discussion.

In the Ambler molecular classification, $\beta$-lactamases are separated into four groups, A through D (Table 3). ${ }^{41}$ Class A enzymes are the most common and include the extended and narrow spectrum TEM and SHV enzymes frequently found in Enterobacteriaceae as well as the CTX-M extended spectrum $\beta$-lactamases now commonly found in E. coli and Klebsiella spp.. ${ }^{41}$ This group also includes a variety of carbapenemases, including KPCs and SMEs. ${ }^{42}$ With the exception of the uncommon inhibitor-resistant TEM (IRT) and complex mutant TEM (CMT) enzymes, all class A enzymes are inhibited in varying degrees by the currently available $\beta$-lactamase inhibitors clavulanate, sulbactam, and tazobactam. ${ }^{43}$ Class B enzymes are metallo- $\beta$-lactamases that rely on a zinc cofactor and are not inhibited by any commercially available therapeutic inhibitors. ${ }^{42}$ Common examples include the VIM, IMP, and NDM carbapenemases. ${ }^{42}$ Class C enzymes are those structurally related to the chromosomal AmpC $\beta$-lactamase of E. coli, which is known to be present and inducible in Enterobacter spp, Citrobacter spp., Serratia spp., P. aeruginosa, and other Enterobacteriaceae. ${ }^{44}$ Although AmpC is chromosomal, a number of plasmid-associated variants have been described, most notably the CMY enzyme. ${ }^{44}$ Induction, derepression, and hyperproduction of chromosomal AmpC and production of plasmid variants such as CMY typically confer clinically relevant resistance to all penicillins and cephems, although the actual MIC varies depending on the relative production of the enzyme and the cephalosporin side-chains. ${ }^{44}$ Some cephalosporins, such as cefepime, are relatively stable to

Table 2 Activity of ceftazidime-avibactam and comparators against select Gram-negative strict anaerobic bacteria ${ }^{27,32,38}$

\begin{tabular}{|c|c|c|c|c|c|c|}
\hline \multirow[t]{2}{*}{ Organism } & \multicolumn{2}{|c|}{ Ceftazidime-avibactam } & \multicolumn{2}{|l|}{ Ceftazidime } & \multicolumn{2}{|c|}{ Ceftriaxone } \\
\hline & $\mathrm{MIC}_{50 / 90}$ & MIC range & $\mathrm{MIC}_{50 / 90}$ & MIC range & $\mathrm{MIC}_{50 / 90}$ & MIC range \\
\hline Bacteroides fragilis & $4 / 32$ & $\leq 0.06->64$ & $0.5 />32$ & $0.5->128$ & $16 / 128$ & N/A \\
\hline Other B. fragilis complex & $32 />128$ & $4->128$ & $>128 />128$ & $8->128$ & $>64 />64$ & N/A \\
\hline Prevotella/Porphyromonas spp. & $2 / 4$ & $\leq 0.125-8$ & $32 />128$ & $0.5->128$ & N/A & N/A \\
\hline Fusobacterium spp. & $\mathrm{N} / \mathrm{A}$ & $\leq 0.06-2$ & $\mathrm{~N} / \mathrm{A}$ & $0.125-32$ & $\mathrm{~N} / \mathrm{A}$ & $\mathrm{N} / \mathrm{A}$ \\
\hline
\end{tabular}

Note: MICs were measured in $\mu \mathrm{g} / \mathrm{mL}$.

Abbreviations: MIC, minimum inhibitory concentration; $\mathrm{MIC}_{50}$, MIC that inhibits $50 \%$ of isolates; $\mathrm{MIC}_{90}$, MIC that inhibits $90 \%$ of isolates; $\mathrm{N} / \mathrm{A}$, not available. 
Table 3 Ambler classification of $\beta$-lactamases ${ }^{41}$

\begin{tabular}{ll}
\hline Ambler classification & Representative examples \\
\hline A & CTX-M, SHV, TEM, KPC, GES, SME \\
B & PER, VEB, IMP, NDM, VIM \\
C & AmpC, FOX, CMY, LAT, ACC, DHA \\
D & OXA enzymes (OXA-I, OXA-48, OXA-I0) \\
\hline
\end{tabular}

AmpC hydrolysis. ${ }^{45}$ Currently available therapeutic inhibitors are minimally active against this class of enzyme. ${ }^{40}$ Class D enzymes are very diverse and are frequently referred to as oxacillinases due to their preferential hydrolysis of oxacillin over penicillin. ${ }^{41}$ Their spectrum is highly variable and may be limited to oxacillin or extended to include all classes of $\beta$-lactams.

Avibactam inactivates susceptible $\beta$-lactamases by covalent acylation of the $\beta$-lactamase active-site serine residue. ${ }^{46,47}$ More recently, it has been demonstrated that the binding is partially reversible, as deacylation slowly follows initial acylation with subsequent recyclization of avibactam's five-membered urea ring. ${ }^{47}$ Since avibactam's ring is recyclized after deacylation rather than hydrolyzed, its activity is fully restored. This differs from other clinically available $\beta$-lactamase inhibitors, since these form irreversible acylenzyme intermediates that decompose through hydrolysis. ${ }^{40}$ In vitro, avibactam inhibits the activity of Ambler class A (eg, ESBL and KPC), class C (eg, AmpC), and some class D (eg, OXA-48) enzymes. ${ }^{22,23,40,48}$ It is not active against metallo$\beta$-lactamases (eg, NDM, VIM, IMP, VEB, PER) due to the absence of the active-site serine residue or against Acinetobacter OXA-type carbapenemases. ${ }^{46,48}$

The half-minimal inhibitory concentration for avibactam against a variety of $\beta$-lactamases has been studied and compared to other commercially available $\beta$-lactamase inhibitors. ${ }^{46,47}$ These studies confirm that avibactam has inhibitory activity against common Class A (SHV, TEM, CTX-M, KPC) enzymes, comparable to or better than clavulanate and tazobactam. Further, avibactam adds Class C (AmpC, FOX, CMY-2, AAC-1) enzymes to its inhibition spectrum. Of note, avibactam has potent inhibitory activity against KPC enzymes that is substantially greater than clavulanate and tazobactam. ${ }^{23}$ The turnover value (the number of molecules required to inhibit a single enzyme) for avibactam has consistently been shown to be 1 , which supports a potency 10 to $>100$ times that of currently available therapeutic inhibitors. ${ }^{40}$

\section{Mechanism of resistance}

The most common mechanism of resistance to ceftazidimeavibactam is the presence or acquisition of a $\beta$-lactamase that is unhindered by avibactam. All class B (metallo-) $\beta$-lactamases are uninhibited by avibactam, and the majority of OXA enzymes are also unaffected by the addition of the drug. ${ }^{46}$ Given the widespread dissemination of such enzymes on plasmids present in Enterobacteriaceae, ${ }^{42}$ these enzymes and their spread remain the primary threat to the clinical use of ceftazidime-avibactam. Although enzymes such as SPM, GIM, and SIM have remained relatively isolated, there are increasing reports of the global emergence of plasmidassociated VIM, IMP, and NDM carbapenemases that are invariably active against ceftazidime-avibactam. ${ }^{42}$

Limited studies are available on the selection of resistance to avibactam in combination with cephalosporins, and none specific to ceftazidime have been published. In one experiment, resistant isolates were selected in vitro at a rate less than $10^{-9}$ among Enterobacteriaceae with preexisting resistance mechanisms to ceftazidime alone. ${ }^{49}$ In one instance, a CTXM-15 enzyme acquired a Lys237Gln mutation, resulting in resistance to ceftaroline-avibactam, and, in another, AmpChyperproducing isolates of Enterobacter cloacae developed an Asn366His mutation of the AmpC enzyme, resulting in resistance to ceftaroline-avibactam. ${ }^{49}$ These experiments clearly confirm that point mutations in existing $\beta$-lactamases can result in the selection of resistant mutants, ostensibly the result of reduced $\beta$-lactamase affinity to avibactam. It is by this manner that diverse $\beta$-lactamases have evolved in response to the introduction of novel $\beta$-lactam antibiotics and inhibitors and the development of such novel enzymes with the introduction of avibactam combinations is virtually assured.

Gram-negative organisms may be resistant to cephalosporins by virtue of mechanisms other than $\beta$-lactamases. Examples include reduced permeability due to porin alterations and efflux mechanisms. ${ }^{50}$ Such mechanisms are not affected by avibactam, and organisms resistant to $\beta$-lactams only by these mechanisms remain resistant despite the addition of avibactam. Frequently, however, such organisms harbor multiple mechanisms of resistance to cephalosporins, including $\beta$-lactamases, in which case avibactam may still be effective in partially restoring ceftazidime susceptibility.

\section{Pharmacokinetics/ pharmacodynamics}

The pharmacokinetics and pharmacodynamics of ceftazidime have been extensively reviewed elsewhere and will not be discussed here. ${ }^{51}$ At present, most of the data describing the pharmacokinetics of avibactam are available only in abstract form. The pharmacokinetic parameters of avibactam following a single intravenous dose in healthy adult volunteers 
are presented in Table 4. ${ }^{52,53}$ Peak plasma concentrations of avibactam have been found to increase in direct proportion to increases in the dose. ${ }^{52}$ In healthy adults, avibactam has a volume of distribution of 20 to $24 \mathrm{~L}$, a terminal half-life of 1.5 to 2.7 hours, and an average clearance of 10.4 to $13.8 \mathrm{~L} /$ hour. $^{52,53}$ The protein binding of avibactam is reported to be $8 \% .^{25}$ Elimination of avibactam is predominantly by renal excretion of unchanged drug. ${ }^{52}$ The pharmacokinetics of avibactam were not statistically altered by coadministration with ceftazidime. ${ }^{52}$ No accumulation of avibactam was apparent following multiple doses administered to healthy adults every 8 hours. ${ }^{54}$ Only marginal differences in pharmacokinetic parameters have been observed based on age and sex. ${ }^{53,55}$ Dosage adjustment on the basis of age or sex is not required..$^{53,55}$ Clearance and central volume of distribution were found to increase by $62 \%$ and $202 \%$, respectively, in patients with complicated intraabdominal infections. ${ }^{56}$ The clinical importance of this observation, if any, is not clear. Epithelial lining fluid concentrations of avibactam were evaluated by Nicolau et al in 43 healthy adult males. ${ }^{57}$ The maximum concentration and area under the concentration-time curve of avibactam in epithelial lining fluid was $28 \%$ to $35 \%$ and $32 \%$ to $35 \%$ of the corresponding values for plasma, respectively. ${ }^{58}$ Further, pulmonary surfactant has not been observed to adversely affect the in vitro activity of ceftazidime-avibactam. ${ }^{58}$ These observations support a potential role for ceftazidime-avibactam in the treatment of pneumonia.

The pharmacokinetics of avibactam have further been evaluated in 24 patients with renal impairment. ${ }^{59}$ As expected, clearance of avibactam declined with declining renal function. The average clearance was $5.8 \pm 1.6 \mathrm{~L} /$ hour, $3.8 \pm 0.6 \mathrm{~L} /$ hour, and $2.2 \pm 0.9 \mathrm{~L} /$ hour in patients with mild (creatinine clearance [CrCl] of 50 to $79 \mathrm{~mL} /$ minute), moderate $(\mathrm{CrCl}$ of 30 to $49 \mathrm{~mL} /$ minute), and severe ( $\mathrm{CrCl}$ of $<30 \mathrm{~mL} /$ minute) renal impairment versus $14.6 \pm 11.2 \mathrm{~L} /$ hour in healthy controls. The corresponding clearance in anuric patients on hemodialysis was $1.0 \pm 0.8 \mathrm{~L} /$ hour. Avibactam clearance during hemodialysis was $9.3 \pm 0.1 \mathrm{~L} /$ hour. Dosage adjustment of avibactam is required in renal impairment, and avibactam should be administered after the completion of hemodialysis on dialysis days. ${ }^{59}$

The pharmacodynamics of avibactam in combination with ceftazidime have been described in several abstracts. Levasseur et al demonstrated inhibition of growth (static effect) of an AmpC-producing E. cloacae isolate and a KPC-producing $K$. pneumoniae isolate with a continuous infusion of $\geq 0.1 \mu \mathrm{g} / \mathrm{mL}$ avibactam in combination with

Table 4 Pharmacokinetic parameters for avibactam administered alone and in combination with ceftazidime

\begin{tabular}{|c|c|c|c|c|c|c|c|c|c|}
\hline \multirow[t]{2}{*}{ Study } & \multirow[t]{2}{*}{ Design } & \multirow{2}{*}{$\begin{array}{l}\text { Study } \\
\text { population }\end{array}$} & \multirow{2}{*}{$\begin{array}{l}\text { Dose } \\
(\mathrm{mg})\end{array}$} & \multicolumn{6}{|c|}{ Pharmacokinetic parameter } \\
\hline & & & & $\begin{array}{l}C_{\max } \\
(\mathrm{mg} / \mathrm{L})\end{array}$ & $\begin{array}{l}\text { AUC } \\
\text { (hours } \times \mathrm{mg} / \mathrm{L} \text { ) }\end{array}$ & $\begin{array}{l}\mathbf{T}_{1 / 2} \\
\text { (hours) }\end{array}$ & VSS (L) & $\begin{array}{l}\mathrm{Cl} \text { (total) } \\
\text { (L/hour) }\end{array}$ & $\begin{array}{l}\mathrm{Cl} \text { (renal) } \\
\text { (L/hour) }\end{array}$ \\
\hline \multirow{7}{*}{$\begin{array}{l}\text { Merdjan } \\
\text { et al }{ }^{52}\end{array}$} & \multirow{7}{*}{$\begin{array}{l}\text { Avibactam IV, } \\
\text { single dose }\end{array}$} & Healthy male & 50 & $2.67(14)$ & $3.72(\mathrm{II})$ & $\mathrm{I} .5(24)$ & $21.1(16)$ & $13.6(13)$ & $12.4(14)$ \\
\hline & & volunteers & 100 & $5.09(33)$ & $8.36(20)$ & I.8 (20) & $24.3(26)$ & $12.4(20)$ & II.4 (22) \\
\hline & & $(n=70)$ & 250 & $12.1(20)$ & $19.7(11)$ & $\mathrm{I} .7(\mathrm{II})$ & $22.9(12)$ & $12.9(11)$ & $15.9(16)$ \\
\hline & & & 500 & $29.0(58)$ & $38.5(27)$ & $1.8(13)$ & $23.9(37)$ & $13.8(25)$ & I3.I (27) \\
\hline & & & 1,000 & $49.6(22)$ & $87.1(16)$ & $2.2(28)$ & $22.1(12)$ & $11.8(17)$ & $11.4(18)$ \\
\hline & & & 1,500 & $10 \mid(2 I)$ & $146(10)$ & $2.7(6)$ & $19.5(14)$ & $10.4(10)$ & $8.7(21)$ \\
\hline & & & 2,000 & $124(23)$ & $186(15)$ & $2.7(5)$ & $21.1(20)$ & II.0(14) & $10.8(2 \mid)$ \\
\hline Merdjan & Avibactam IV & Healthy male & 250 & I $3.4(29)$ & $21.0(15)$ & $1.8(10)$ & $21.8(32)$ & $12.2(18)$ & $12.3(32)$ \\
\hline et $\mathrm{al}^{52}$ & $\begin{array}{l}\text { administered } \\
\text { concurrently with } \\
\text { ceftazidime ( } 1: 4 \text { ratio) }\end{array}$ & $\begin{array}{l}\text { volunteers } \\
(n=20)\end{array}$ & 500 & $24.0(26)$ & $38.2(22)$ & $1.8(10)$ & $26.2(26)$ & $13.6(19)$ & $13.0(22)$ \\
\hline $\begin{array}{l}\text { Tarral } \\
\text { et } \mathrm{al}^{53}\end{array}$ & $\begin{array}{l}\text { Avibactam IV, } \\
\text { single dose }\end{array}$ & $\begin{array}{l}\text { Healthy males, } \\
\text { mean age of } \\
28.7 \text { years }(n=9)\end{array}$ & 500 & $33.8(4.24)$ & $49.9(6.3)$ & $2.1(0.64)$ & ND & $10.2(1.2)$ & $9.2(4.0)$ \\
\hline $\begin{array}{l}\text { Tarral } \\
\text { et } \mathrm{al}^{53}\end{array}$ & $\begin{array}{l}\text { Avibactam IV, } \\
\text { single dose }\end{array}$ & $\begin{array}{l}\text { Healthy females, } \\
\text { mean age of } \\
30.9 \text { years }(n=8)\end{array}$ & 500 & $36.9(9.3)$ & 49.8 (9.1) & $1.7(0.09)$ & ND & $10.3(1.8)$ & $8.6(1.6)$ \\
\hline $\begin{array}{l}\text { Tarral } \\
\text { et } \mathrm{al}^{53}\end{array}$ & $\begin{array}{l}\text { Avibactam IV, } \\
\text { single dose }\end{array}$ & $\begin{array}{l}\text { Elderly males, } \\
\text { mean age of } \\
68.8 \text { years }(n=8)\end{array}$ & 500 & $26.5(5.7)$ & $52.4(9.4)$ & $3.2(0.65)$ & ND & $9.8(1.8)$ & $6.9(3.6)$ \\
\hline $\begin{array}{l}\text { Tarral } \\
\text { et } \mathrm{al}^{53}\end{array}$ & $\begin{array}{l}\text { Avibactam IV, } \\
\text { single dose }\end{array}$ & $\begin{array}{l}\text { Elderly females, } \\
\text { mean age of } \\
69.1 \text { years }(n=8)\end{array}$ & 500 & 38.4 (I5.5) & $66.2(15.0)$ & $2.4(0.47)$ & ND & $8.0(2.2)$ & 4.5 (I.8) \\
\hline
\end{tabular}

Note: All values expressed represent the mean with the percent (\%) coefficient of variation ${ }^{52}$ or standard deviation ${ }^{53}$ in parentheses. 
simulated serum concentrations of ceftazidime. ${ }^{60}$ Noel et al evaluated the antibacterial effect of a continuous infusion of avibactam at different concentrations in combination with simulated serum concentrations of ceftazidime ( $2 \mathrm{~g}$ intravenously every 8 hours) using a dilutional, single-compartment pharmacokinetic model ${ }^{61}$ Three strains of Enterobacteriaceae were evaluated: a CTX-M-15 producing E. coli, an AmpC producing E. cloacae, and a KPC producing K. pneumoniae. Maximum killing by ceftazidime at 24 hours as determined by the area under the bacterial kill curve was observed with an avibactam continuous infusion of $\geq 2 \mu \mathrm{g} / \mathrm{mL}$ for the CTX-M and AmpC producers and $\geq 2$ to $4 \mu \mathrm{g} / \mathrm{mL}$ for the KPC producer. Avibactam dosing of $500 \mathrm{mg}$ intravenously every 8 hours would be expected to achieve the equivalent desired exposure in humans. Similarly, Bowker et al evaluated simulated serum concentrations of ceftazidime (2 $\mathrm{g}$ intravenously every 8 hours) in combination with a continuous infusion of avibactam at different concentrations. ${ }^{62}$ A single-compartment dilutional pharmacokinetic in vitro model was used and an AmpC-producing E. cloacae isolate was the target pathogen. These investigators reported $a \geq 2 \log$ reduction in bacterial counts at 48 hours with ceftazidime combined with avibactam infused at a concentration of 4 $\mu \mathrm{g} / \mathrm{mL}^{62}$ In humans, serum bactericidal activity of ceftazidime versus a ceftazidime-resistant $K$. pneumoniae isolate (ceftazidime MIC of $32 \mu \mathrm{g} / \mathrm{mL}$ ) has been observed for up to 8 hours following infusion of $1 \mathrm{~g}$ ceftazidime with $250 \mathrm{mg}$ avibactam, and for up to 12 hours following infusion of $2 \mathrm{~g}$ ceftazidime with $500 \mathrm{mg}$ avibactam. ${ }^{52}$

\section{Animal models of Gram-negative bacterial infection}

Ceftazidime combined with avibactam has demonstrated efficacy in several animal models of infection due to ceftazidime-non-susceptible Gram-negative bacteria. ${ }^{25,63-67}$ As with the previous pharmacokinetic/pharmacodynamic data, most of the studies described here are available only in abstract form. The combination of ceftazidime and avibactam has been evaluated by Endimiani et al in murine models of septicemia and thigh infection. ${ }^{65}$ These investigators assessed the efficacy of ceftazidime-avibactam versus two KPC-producing K. pneumoniae strains, both of which demonstrated an MIC to ceftazidime alone of $\geq 256 \mu \mathrm{g} / \mathrm{mL}$. In the murine lethal septicemia model, treatment with a single subcutaneous dose of ceftazidime-avibactam in a ratio of 4:1 reduced the median effective ceftazidime dose for $50 \%$ of animals $\left(\mathrm{ED}_{50}\right)$ from $1,578 \mathrm{mg} / \mathrm{kg}$ (first isolate) and $709 \mathrm{mg} /$ $\mathrm{kg}$ (second isolate) to $15.1 \mathrm{mg} / \mathrm{kg}$ and $3.8 \mathrm{mg} / \mathrm{kg}$, respectively.
Survival of test animals in this model approached $100 \%$ for ceftazidime-avibactam (ratio of $4: 1$ ) at a dose of $32 / 8 \mathrm{mg} / \mathrm{kg}$. This contrasted with a survival of $0 \%$ for test animals treated only with ceftazidime at a dose of up to $256 \mathrm{mg} / \mathrm{kg}$. In the neutropenic thigh infection model, mice treated with ceftazidime-avibactam at doses of $\geq 128 / 32 \mathrm{mg} / \mathrm{kg}$ demonstrated $\mathrm{a}>2 \log _{10}$ colony forming units (CFU) reduction in thighs removed 24 hours post-infection. In contrast, ceftazidime alone was unable to reduce the numbers of CFUs at doses of $\geq 1,024 \mathrm{mg} / \mathrm{kg}$. ${ }^{65}$ Similarly, Levasseur et al evaluated ceftazidime-avibactam in a murine septicemia model with extended spectrum and AmpC-producing Enterobacteriaceae isolates as the challenge organisms (ceftazidime MIC of $32 \mu \mathrm{g} / \mathrm{mL}$ to $>128 \mu \mathrm{g} / \mathrm{mL}$ ) ${ }^{64}$ Ceftazidime-avibactam was administered in a $4: 1$ weight ratio. The $\mathrm{ED}_{50}$ for ceftazidime-avibactam ranged from 2 to $27 \mathrm{mg} / \mathrm{kg}$ depending on the test strain, in contrast to $>60 \mathrm{mg} / \mathrm{kg}$ for ceftazidime alone. ${ }^{64}$

Merdjan et al studied ceftazidime-avibactam in a murine pneumonia model. ${ }^{63}$ Pneumonia was induced by intratracheal inoculation of an AmpC- and SHV-11-producing K. pneumoniae isolate. Ceftazidime-avibactam was administered at a dose of $150 / 37.5 \mathrm{mg} / \mathrm{kg}$ every 8 hours subcutaneously starting 16 hours post-infection for a duration of 2 days. At 48 hours post-treatment, mean lung bacterial counts in untreated mice were $11 \log _{10}$ CFU. Mean lung bacterial counts were reduced to $7.9 \log _{10} \mathrm{CFU}$ with ceftazidime monotherapy and $4.5 \log _{10}$ CFU with ceftazidime in combination with avibactam. ${ }^{63}$ Borgonovi et al assessed ceftazidime in combination with avibactam in an immunosuppressed mouse model of kidney infection caused by AmpC- or ESBL-producing Enterobacteriaceae isolates. ${ }^{67}$ The ceftazidime MIC of the test organisms ranged from 16 to $>128 \mu \mathrm{g} / \mathrm{mL}$. At a dose range of 10 to $25 \mathrm{mg} / \mathrm{kg}$ administered subcutaneously $4,8,24$, and 32 hours post-infection, ceftazidime-avibactam (ratio of $4: 1$ ) reduced the kidney bacterial burden at 48 hours by 2.6 to 4.5 $\log _{10}$ CFU compared with ceftazidime alone $(P<0.05) .{ }^{67}$

Ceftazidime in combination with avibactam has been evaluated by Cottagnoud et al in a rabbit meningitis model. ${ }^{68}$ Rabbits were inoculated intracisternally with an AmpC-producing K. pneumoniae isolate that had an MIC for ceftazidime of $>128 \mu \mathrm{g} / \mathrm{mL}$. Eight hours post-infection, the animals were treated with ceftazidime $150 \mathrm{mg} / \mathrm{kg}$ intravenously (alone or in combination with $37.5 \mathrm{mg} / \mathrm{kg}$ avibactam) or meropenem $125 \mathrm{mg} / \mathrm{kg}$ intravenously. Ceftazidime monotherapy was unable to reduce the cerebrospinal fluid (CSF) bacterial load. In contrast, over a time period of 8 hours, treatment with meropenem reduced the CSF bacterial load by a mean of $4.23 \log _{10}$ CFU, while ceftazidime combined with avibactam reduced the 
bacterial load by a mean of $5.66 \log _{10}$ CFU. The mean CSF penetration of avibactam in rabbits was $38 \% .{ }^{66}$

Finally, Crandon et al evaluated ceftazidime in combination with avibactam versus $P$. aeruginosa in a neutropenic and immunocompetent murine thigh infection model. ${ }^{25}$ A free ceftazidime-avibactam drug concentration-time profile simulating that seen in humans with a ceftazidime dose of $2 \mathrm{~g}$ intravenously every 8 hours and an avibactam dose of $500 \mathrm{mg}$ intravenously every 8 hours was assessed. In the neutropenic mouse studies, human-simulated doses of ceftazidime-avibactam resulted in a reduction in thigh bacterial density of $\geq 0.5 \log _{10}$ CFU for 22 of 27 isolates (16/17 isolates with a ceftazidime-avibactam MIC of $\leq 8 \mu \mathrm{g} / \mathrm{mL}$ and $5 / 8$ isolates with a ceftazidime-avibactam MIC of $16 \mu \mathrm{g} / \mathrm{mL}$ ) in contrast to 10 of 27 isolates for ceftazidime alone. In immunocompetent animals, ceftazidime-avibactam demonstrated efficacy versus all isolates, with a range in thigh bacterial reduction of 0.3 to $1.95 \log _{10} \mathrm{CFU}$. In contrast, ceftazidime alone resulted in a reduction in bacterial density of $\geq 0.3 \log _{10}$ CFU for only 10 of 15 isolates. ${ }^{25}$
In summary, ceftazidime in combination with avibactam has demonstrated significant bacterial killing/efficacy in a number of animal models of infection. These have included murine models of sepsis, thigh infection, pneumonia, and kidney infection, and a rabbit model of meningitis due to ceftazidime-non-susceptible Enterobacteriaceae isolates. Further, ceftazidime-avibactam displayed significantly improved bacterial killing over ceftazidime alone in a murine thigh model of infection with $P$. aeruginosa. These data support a potential role for the combination of ceftazidime and avibactam in the treatment of infections caused by Gram-negative bacteria in general, and ceftazidime-non-susceptible pathogens in particular.

\section{Clinical trial data}

To date, there have only been two published clinical trials evaluating the efficacy of ceftazidime in combination with avibactam for infections caused, in whole or in part, by Gram-negative bacilli (Table 5). ${ }^{24,68}$ Lucasti et al performed a Phase II prospective, randomized, double-blind trial evaluating ceftazidime-avibactam and metronidazole versus meropenem

Table 5 Phase II clinical trials evaluating ceftazidime in combination with avibactam for Gram-negative bacterial infections

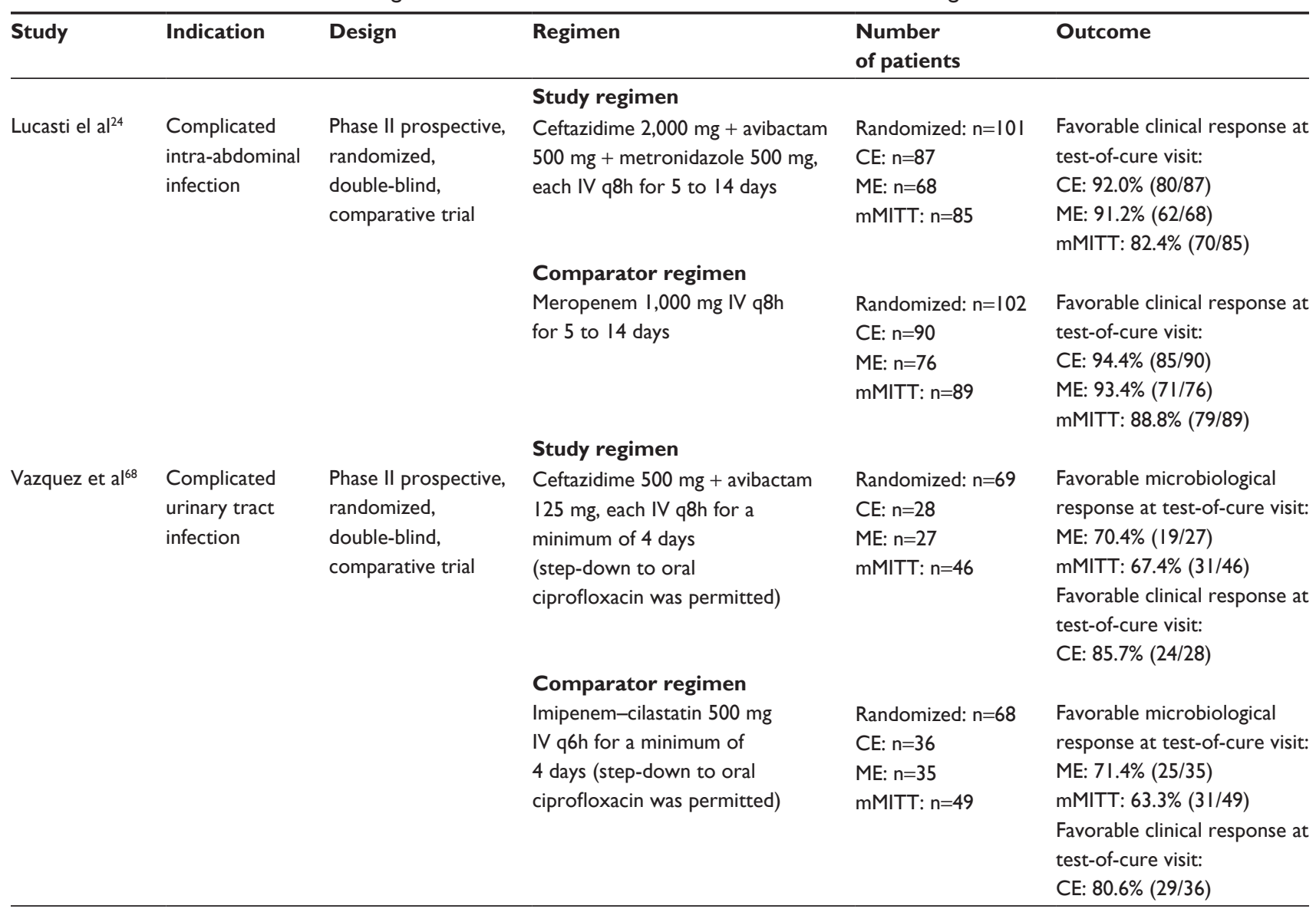

Abbreviations: CE, clinically evaluable; IV, intravenously; ME, microbiologically evaluable; mMITT, microbiologically modified intent to treat; q6h, every 6 hours; q8h, every 8 hours. 
for the treatment of adults with complicated intra-abdominal infections. ${ }^{24}$ Briefly, adult patients with evidence of a complicated intra-abdominal infection requiring both surgical intervention and antimicrobial therapy were eligible for inclusion. Patients with infections caused by pathogens known to be resistant to the study agents were excluded. The primary study outcome was the clinical response in the microbiologically evaluable population 2 weeks following the last dose of study medication (test-of-cure visit). In total, 203 patients were enrolled into the trial. The most common sites of infection were appendix (47\%) and stomach/duodenum (26\%), and the majority of patients (83\%) had an Acute Physiology And Chronic Health Evaluation (APACHE) ${ }^{24}$ II score of $\leq 10$. Polymicrobial infection was present in $38 \%$ of patients. One hundred fifty-three aerobic/facultative Gram-negative pathogens were recovered, with $E$. coli being the most frequent $(69 \%$ [105/153]). The major results of this study are summarized in Table 5. For the primary study end point, a favorable clinical response in the microbiologically evaluable population was observed in $91.2 \%$ of patients $(62 / 68)$ treated with ceftazidime-avibactam plus metronidazole versus $93.4 \%$ of patients (71/76) treated with meropenem (observed difference of $-0.3 \%, 95 \%$ confidence interval $[\mathrm{CI}]$ : $-17.1 \%$ to $15.4 \%$ ). A favorable microbiological response was observed in $96.2 \%$ of patients $(25 / 26)$ treated with ceftazidime-avibactam who were infected with a ceftazidime-intermediate or -resistant Gram-negative isolate at baseline. ${ }^{24}$

Vazquez et al conducted a Phase II prospective, randomized, double-blind trial evaluating ceftazidime-avibactam versus imipenem for the treatment of adults with complicated urinary tract infections due to Gram-negative bacteria. ${ }^{68}$ Adult patients with either acute pyelonephritis or another complicated urinary tract infection caused by a Gramnegative pathogen were eligible for inclusion. Patients with an infection caused by a uropathogen resistant to one or both study drugs were excluded. The primary study outcome was a favorable microbiological response 5 to 9 days after the last dose of therapy (test-of-cure visit) in the microbiologically evaluable population. In total, 137 patients were randomized to receive therapy. Acute pyelonephritis was the primary diagnosis in $62 \%$ of trial participants. In the microbiologically evaluable population, $E$. coli was the uropathogen in $93.5 \%$ of participants $(58 / 62)$. The major results of the study are summarized in Table 5. For the primary study end point, a favorably microbiological response was found in $70.4 \%$ $(19 / 27)$ of patients treated with ceftazidime-avibactam in comparison with $71.4 \%(25 / 35)$ treated with imipenem (difference of $-1.1 \%, 95 \% \mathrm{CI}$ : $-27.2 \%$ to $25 \%$ ). Among patients with a ceftazidime-resistant uropathogen, a favorable microbiological response was observed at the test-ofcure visit in $85.7 \%(6 / 7)$ of those who were treated with ceftazidime-avibactam. ${ }^{68}$

There are several important limitations to the above trials. Most importantly, both trials included a relatively small number of participants. As these were Phase II trials, neither was statistically powered to demonstrate noninferiority. As a consequence of the small sample sizes, the range of bacterial pathogens recovered in these studies was relatively limited. E. coli accounted for the majority of facultative Gram-negative isolates in both of the studies. Klebsiella spp. were infrequently recovered in the intra-abdominal infection study and not recovered at all in the urinary infection study. Further, while ceftazidime non-susceptible isolates were recovered in both studies, no details were provided regarding specific mechanisms of resistance (eg, ESBL production, AmpC production, KPC production, other). While the results of these studies are encouraging and appear to support a role for ceftazidime-avibactam in the treatment of Gram-negative infections, further data from Phase III trials are required.

\section{Safety}

There are limited safety data available on the use of ceftazidime-avibactam in humans. In Phase I studies as well as the two published, Phase II clinical trials, the combination of ceftazidime and avibactam was generally well tolerated. ${ }^{24,52,53,68}$ Adverse events were observed in $64.4 \%$ of patients receiving ceftazidime-avibactam plus metronidazole versus $57.8 \%$ of those receiving meropenem in the intra-abdominal infection study carried out by Lucasti et al. ${ }^{24}$ In this trial, the most common adverse events reported among patients receiving ceftazidime-avibactam plus metronidazole were nausea, vomiting, abdominal pain, pyrexia, and elevations in liver enzymes. Most of these adverse events were mild to moderate in severity and it is quite possible that some may have been related to the underlying medical condition being treated or metronidazole (particularly the gastrointestinal adverse events). One serious case of elevated liver enzymes in the ceftazidime-avibactam plus metronidazole arm was considered to be medication related. ${ }^{24}$ In the Phase II urinary infection trial by Vazquez et al, adverse events were observed in $67.6 \%$ of patients receiving ceftazidime-avibactam versus $76.1 \%$ of those receiving imipenem-cilastatin. ${ }^{68}$ The most common adverse events reported among those receiving ceftazidime-avibactam were headache, gastrointestinal symptoms, and injection-/infusion-site reactions. Two serious adverse events considered to be drug related occurred among 
patients receiving ceftazidime-avibactam: a case of renal failure and a case of significant diarrhea ${ }^{68}$

The effect of ceftazidime-avibactam administered in supratherapeutic doses on cardiac repolarization has been assessed by Edeki et al. ${ }^{69}$ These investigators performed a double-blind, randomized, placebo-controlled four-way crossover study in healthy males. Subjects were administered ceftazidime-avibactam at a dose of 3,000/2,000 mg, infused over 30 minutes. Electrocardiogram readings were obtained at various time points between 30 minutes and 12 hours after the infusion. Comparing ceftazidime-avibactam with placebo, there was no significant change from baseline in the Fridericia-corrected QT interval. ${ }^{69}$

To summarize, while the data available to date have not demonstrated significant safety concerns for the combination of ceftazidime and avibactam, assessment of safety is significantly limited by the small number of human subjects in whom this combination has been administered. An accurate safety assessment will require review of data from Phase III clinical trials and, if marketed, postmarketing surveillance. It should be noted that all of the adverse events associated with ceftazidime monotherapy would be expected to occur with the administration of ceftazidime-avibactam. These have been extensively reviewed elsewhere and will not be described in detail here, but may include thrombophlebitis/injection-site reactions, gastrointestinal side effects, mild hematologic abnormalities (eg, eosinophilia), and transient elevation in liver enzymes. ${ }^{51}$

\section{Conclusion}

The addition of avibactam to ceftazidime improves its activity against Enterobacteriaceae and $P$. aeruginosa because avibactam inhibits isolates with serine $\beta$-lactamases, including ESBL, AmpC, and KPC enzymes. However, avibactam does not improve the activity of ceftazidime against Acinetobacter spp., Burkholderia spp., or most anaerobic Gram-negative rods. Pharmacodynamic data indicate that ceftazidime-avibactam is bactericidal at concentrations achievable in human serum. Animal studies demonstrate that ceftazidime-avibactam is effective in ceftazidime-resistant Gram-negative septicemia, meningitis, pyelonephritis, and pneumonia. The limited clinical trials published to date have reported that ceftazidime-avibactam is as effective as therapy with a carbapenem in complicated urinary tract infection and complicated intra-abdominal infection (combined with metronidazole), including infection caused by cephalosporin-resistant Gram-negative isolates. Safety and tolerability of ceftazidime-avibactam in clinical trials has been excellent, with few serious drug-related adverse events reported; published data suggest that no additional considerations need to be taken when dosing ceftazidime-avibactam compared to ceftazidime alone. Given the abundant clinical experience with ceftazidime and the significant improvement that avibactam provides in its activity against contemporary $\beta$-lactamase-producing Gram-negative pathogens, it is likely this new combination agent will play a role in the empiric monotherapy of complicated urinary tract infection caused or suspected to be caused by antimicrobial-resistant pathogens (eg, ESBL-, AmpC-, or KPC-producing Enterobacteriaceae and multidrug-resistant $P$. aeruginosa), and in combination with metronidazole for polymicrobial intra-abdominal infections. Ceftazidime-avibactam may also represent salvage therapy after treatment failure with a third-generation cephalosporin or for documented infections due to Gram-negative bacilli producing ESBL, KPC, and/or AmpC enzymes. In addition, because of its increased activity versus $P$. aerugi$n o s a$, it may prove useful in the treatment of suspected and documented $P$. aeruginosa infections. Potential future uses may include hospital-acquired pneumonia (in combination with antistaphylococcal and anti-pneumococcal agents) or treatment of skin and soft tissue infections caused by antimicrobial-resistant Gram-negative pathogens (eg, diabetic foot infections), but further clinical trials are required.

\section{Disclosure}

The authors report no conflicts of interest in this work.

\section{References}

1. Andes DE, Craig WA. Cephalosporins. In: Mandell GL, Bennett JE, Dolin R, editors. Mandell, Douglas, and Bennett's Principles and Practice of Infectious Diseases. 7th ed. Philadelphia, PA: Churchill Livingstone Elsevier; 2010:323-337.

2. Pitout JD. Infections with extended-spectrum beta-lactamase-producing enterobacteriaceae: changing epidemiology and drug treatment choices. Drugs. 2010;70:313-333.

3. Bush K. Alarming beta-lactamase-mediated resistance in multidrugresistant Enterobacteriaceae. Curr Opin Microbiol. 2010;13:558-564.

4. Livermore DM, Woodford N. The beta-lactamase threat in Enterobacteriaceae, Pseudomonas and Acinetobacter. Trends Microbiol. 2006; 14:413-420.

5. Livermore DM. Has the era of untreatable infections arrived? J Antimicrob Chemother. 2009;64 Suppl 1:i29-i36.

6. Turner PJ. MYSTIC Europe 2007: activity of meropenem and other broad-spectrum agents against nosocomial isolates. Diagn Microbiol Infect Dis. 2009;63:217-222.

7. Hawser SP, Badal RE, Bouchillon SK, Hoban DJ. Trending eight years of in vitro activity of ertapenem and comparators against Escherichia coli from intra-abdominal infections in North America - SMART 2002-2009. J Chemother. 2011;23:266-272.

8. Hoban DJ, Nicolle LE, Hawser S, Bouchillon S, Badal R. Antimicrobial susceptibility of global inpatient urinary tract isolates of Escherichia coli: results from the Study for Monitoring Antimicrobial Resistance Trends (SMART) program: 2009-2010. Diagn Microbiol Infect Dis. 2011;70: 507-511. 
9. Aszodi J, Fromentin C, Lampilas M, et al; Aventis Pharma SA, assignee. Heterocyclic compounds which are active as inhibitors of $\beta$-lactamases, 2003. International Patent number PCT/FR2003/000243. Jan 27, 2003.

10. Coleman K. Diazabicyclooctanes (DBOs): a potent new class of nonbeta-lactam beta-lactamase inhibitors. Curr Opin Microbiol. 2011;14: $550-555$.

11. AztraZeneca. Ceftazidime-Avibactam Compared With Doripenem Followed by Oral Therapy for Hospitalized Adults With Complicated UTIs (Urinary Tract Infections). Available from: http://clinicaltrials.gov/ ct2/show/NCT01595438. NLM Identifier: NCT01595438. Accessed November 26, 2013.

12. AztraZeneca. Compare Ceftazidime-Avibactam and Doripenem Followed by Oral Therapy for Hospitalized Adults With Complicated UTIs (Urinary Tract Infections). Available from: http://clinicaltrials.gov/ ct2/ show/NCT01599806. NLM Identifier: NCT01599806. Accessed November 26, 2013.

13. AstraZeneca. Compare Ceftazidime-Avibactam + Metronidazole Versus Meropenem for Hospitalized Adults With Complicated IntraAbdominal Infections. Available from http://clinicaltrials.gov/ct2/ show/ NCT01499290. NLM Identifier: NCT01499290. Accessed November 26, 2013.

14. AstraZeneca. A Study Comparing Ceftazidime-Avibactam+ Metronidazole Versus Meropenem in Adults With Complicated Intraabdominal Infections. Available from: http://clinicaltrials.gov/ct2/show/ NCT01500239. NLM Identifier: NCT01500239. Accessed November 26, 2013.

15. Beale JM Jr. Antibacterial antibiotics. In: Beale JM Jr, Block J, editors. Wilson and Gisvold's Textbook of Organic Medicinal and Pharmaceutical Chemistry. 12th ed. Baltimore, MD: Lippincott Williams and Wilkins; 2011:258-329.

16. Dunn GL. Ceftizoxime and other third-generation cephalosporins: structure-activity relationships. JAntimicrob Chemother. 1982;10 SupplC: $1-10$.

17. Caprile KA. The cephalosporin antimicrobial agents: a comprehensive review. J Vet Pharmacol Ther. 1988;11:1-32.

18. Neu HC. beta-Lactam antibiotics: structural relationships affecting in vitro activity and pharmacologic properties. Rev Infect Dis. 1986; 8 Suppl 3:S237-S259.

19. Neu HC. Beta-lactamase stability of cefoxitin in comparison with other beta-lactam compounds. Diagn Microbiol Infect Dis. 1983;1:313-316.

20. Miossec C, Merdjan H, Hodgson J. Safety and toxicokinetics of NXL104, a broad spectrum $\beta$-lactamase inhibitor, in the rat [abstract no F-1461]. Paper presented at: 45th Annual Interscience Conference on Antimicrobial Agents and Chemotherapy; December 16-19, 2005; Washington, DC.

21. Miossec C. Progress of a novel non-beta-lactam beta-lactamase inhibitor towards the clinic. Paper presented at: The Challenge of Antimicrobial Drug Development - Integrating Chemistry and Biology; March 21-22, 2007; San Diego, CA.

22. Aktas Z, Kayacan C, Oncul O. In vitro activity of avibactam (NXL104) in combination with beta-lactams against Gram-negative bacteria, including OXA-48 beta-lactamase-producing Klebsiella pneumoniae. Int J Antimicrob Agents. 2012;39:86-89.

23. Stachyra T, Levasseur P, Péchereau MC, et al. In vitro activity of the \{beta\}-lactamase inhibitor NXL104 against KPC-2 carbapenemase and Enterobacteriaceae expressing KPC carbapenemases. JAntimicrob Chemother. 2009;64:326-329.

24. Lucasti C, Popescu I, Ramesh MK, Lipka J, Sable C. Comparative study of the efficacy and safety of ceftazidime/avibactam plus metronidazole versus meropenem in the treatment of complicated intra-abdominal infections in hospitalized adults: results of a randomized, double-blind, Phase II trial. J Antimicrob Chemother. 2013;68:1183-1192.

25. Crandon JL, Schuck VJ, Banevicius MA, et al. Comparative in vitro and in vivo efficacies of human simulated doses of ceftazidime and ceftazidime-avibactam against Pseudomonas aeruginosa. Antimicrob Agents Chemother. 2012;56:6137-6146.
26. Levasseur P, Girard AM, Claudon M, et al. In vitro antibacterial activity of the ceftazidime-avibactam (NXL104) combination against Pseudomonas aeruginosa clinical isolates. Antimicrob Agents Chemother. 2012;56:1606-1608.

27. Citron DM, Tyrrell KL, Merriam V, Goldstein EJ. In vitro activity of ceftazidime-NXL104 against 396 strains of beta-lactamase-producing anaerobes. Antimicrob Agents Chemother. 2011;55:3616-3620.

28. Curcio D. Activity of a novel combination against multidrug-resistant nonfermenters: ceftazidime plus NXL104. Expert Rev Anti Infect Ther. 2011;9:173-176.

29. Walkty A, DeCorby M, Lagacé-Wiens PR, Karlowsky JA, Hoban DJ, Zhanel GG. In vitro activity of ceftazidime combined with NXL104 versus Pseudomonas aeruginosa isolates obtained from patients in Canadian hospitals (CANWARD 2009 study). Antimicrob Agents Chemother. 2011;55:2992-2994.

30. Mushtaq S, Warner M, Livermore DM. In vitro activity of ceftazidime+NXL104 against Pseudomonas aeruginosa and other non-fermenters. J Antimicrob Chemother. 2010;65:2376-2381.

31. Sader HS, Flamm RK, Jones RN. Antimicrobial activity of ceftarolineavibactam tested against clinical isolates collected from US. Medical Centers in 2010-2011. Antimicrob Agents Chemother. 2013;57: 1982-1988.

32. Zhanel GG, Lawson CD, Adam H, et al. Ceftazidime-avibactam: a novel cephalosporin/ $\beta$-lactamase inhibitor combination. Drugs. 2013;73: 159-177.

33. Lagacé-Wiens PR, Tailor F, Simner P, et al. Activity of NXL104 in combination with beta-lactams against genetically characterized Escherichia coli and Klebsiella pneumoniae isolates producing class A extended-spectrum beta-lactamases and class $\mathrm{C}$ beta-lactamases. Antimicrob Agents Chemother. 2011;55:2434-2437.

34. Endimiani A, Choudhary Y, Bonomo RA. In vitro activity of NXL104 in combination with beta-lactams against Klebsiella pneumoniae isolates producing KPC carbapenemases. Antimicrob Agents Chemother. 2009;53:3599-3601.

35. Karlowsky JA, Adam HJ, Baxter MR, et al. In vitro activity of ceftaroline-avibactam against Gram-negative and Gram-positive pathogens isolated from patients in Canadian hospitals in 2010-2012: results from the CANWARD Surveillance Study. Antimicrob Agents Chemother. 2013;57:5600-5611.

36. Walkty A, Karlowsky JA, Adam H, et al. In vitro activity of ceftolozane/ tazobactam versus Pseudomonas aeruginosa isolates obtained from patients in Canadian hospitals: CANWARD 2007-2012. Antimicrob Agents Chemother. 2013.

37. Hancock RE. Resistance mechanisms in Pseudomonas aeruginosa and other nonfermentative gram-negative bacteria. Clin Infect Dis. 1998; 27 Suppl 1:S93-S99.

38. Dubreuil LJ, Mahieux S, Neut C, Miossec C, Pace J. Anti-anaerobic activity of a new $\beta$-lactamase inhibitor NXL104 in combination with $\beta$-lactams and metronidazole. Int J Antimicrob Agents. 2012;39: 500-504.

39. Hayes MV, Orr DC. Mode of action of ceftazidime: affinity for the penicillin-binding proteins of Escherichia coli K12, Pseudomonas aeruginosa and Staphylococcus aureus. J Antimicrob Chemother. 1983;12:119-126.

40. Stachyra T, Péchereau MC, Bruneau JM, et al. Mechanistic studies of the inactivation of TEM-1 and P99 by NXL104, a novel non-beta-lactam beta-lactamase inhibitor. Antimicrob Agents Chemother. 2010;54: 5132-5138.

41. Bush K. The ABCD's of beta-lactamase nomenclature. J Infect Chemother. 2013;19:549-559.

42. Queenan AM, Bush K. Carbapenemases: the versatile beta-lactamases. Clin Microbiol Rev. 2007;20:440-458, Table of contents.

43. Cantón R, Morosini MI, de la Maza OM, de la Pedrosa EG. IRT and CMT beta-lactamases and inhibitor resistance. Clin Microbiol Infect. 2008;14 Suppl 1:53-62.

44. Jacoby GA. AmpC beta-lactamases. Clin Microbiol Rev. 2009;22: 161-182, Table of Contents. 
45. Livermore DM. Defining an extended-spectrum beta-lactamase. Clin Microbiol Infect. 2008;14 Suppl 1:3-10.

46. Ehmann DE, Jahic H, Ross PL, et al. Kinetics of avibactam inhibition against class $\mathrm{A}, \mathrm{C}$, and $\mathrm{D}$ beta-lactamases. $J$ Biol Chem. 2013;288:27960-27971.

47. Ehmann DE, Jahic H, Ross PL, et al. Avibactam is a covalent, reversible, non-beta-lactam beta-lactamase inhibitor. Proc Natl Acad Sci U S A. 2012;109:11663-11668

48. Mushtaq S, Warner M, Williams G, Critchley I, Livermore DM. Activity of chequerboard combinations of ceftaroline and NXL104 versus betalactamase-producing Enterobacteriaceae. J Antimicrob Chemother. 2010;65:1428-1432.

49. Livermore DM, Mushtaq S, Barker K, Hope R, Warner M, Woodford N. Characterization of beta-lactamase and porin mutants of Enterobacteriaceae selected with ceftaroline + avibactam (NXL104). J Antimicrob Chemother. 2012;67:1354-1358.

50. Pfeifer Y, Cullik A, Witte W. Resistance to cephalosporins and carbapenems in Gram-negative bacterial pathogens. Int $J$ Med Microbiol. 2010;300:371-379.

51. Richards DM, Brogden RN. Ceftazidime. A review of its antibacterial activity, pharmacokinetic properties and therapeutic use. Drugs. 1985;29:105-161.

52. Merdjan H, Tarral A, Girard AM, et al. Safety, single dose pharmacokinetics, and pharmacodynamics of $\beta$-lactamase inhibitor NXL104 in healthy young male adults [abstract A-809]. Paper presented at: 47th Annual Interscience Conference on Antimicrobial Agents and Chemotherapy; September 17-20, 2007; Chicago, IL.

53. Tarral A, Lipka J, Gyaw S, et al. Effect of age and gender on the pharmacokinetics (PK) and safety of NXL104 in health subjects (protocol NXL104/1004) [abstract A1-007]. Paper presented at: 49th Annual Interscience Conference on Antimicrobial Agents and Chemotherapy September 12-15, 2009; San Francisco, CA.

54. Edeki T, Armstrong J. Pharmacokinetics of avibactam (AVI) and ceftazidime (CAZ) following separate or combined administration in healthy volunteers [abstract A-1019]. 53rd Annual Interscience Conference on Antimicrobial Agents and Chemotherapy; September 10-13, 2013; Denver, CO.

55. Felices M, Gualano V, Tarral A, Sable C, Merdjan H. Combined population pharmacokinetic analysis of four phase 1studies with NXL104 [abstract P1599]. 20th European Congress of Clinical Microbiology and Infectious Diseases; April 10-13, 2010; Vienna, Austria.

56. Li J, Knebel W, Riggs M, Zou D, Nichols W, Das S. Population pharmacokinetic modeling of ceftazidime (CAZ) and avibactam (AVI) in healthy volunteers and patients with complicated intra-abdominal infection (cIAI) [abstract A-634]. 52nd Annual Interscience Conference on Antimicrobial Agents and Chemotherapy; September 9-12, 2012; San Francisco, CA.

57. Nicolau DP, Siew L, Armstrong J, Edeki T, Bouw R. Concentration of avibactam (AVI) and ceftazidime (CAZ) in plasma and epithelial lining fluid (ELF) in healthy volunteers [abstract A-1027]. 53rd Annual Interscience Conference on Antimicrobial Agents and Chemotherapy; September 10-13, 2013; Denver, CO.

58. Huband MD, Otterson LG, Andrews B, Nichols WW. Effect of pulmonary surfactant on the in vitro antibacterial activity of ceftazidimeavibactam [abstract E-1170]. 53rd Annual Interscience Conference on Antimicrobial Agents and Chemotherapy; September 10-13, 2013; Denver, CO.

\section{Core Evidence}

\section{Publish your work in this journal}

Core Evidence is an international, peer-reviewed open-access journal evaluating the evidence underlying the potential place in therapy of drugs throughout their development lifecycle from preclinical to postlaunch. The focus of each review is to evaluate the case for a new drug or class in outcome terms in specific indications and patient groups.
59. Merdjan H, Tarral A, Haazen W, Evene E, Robertson M, Sable C. Pharmacokinetics and tolerability of NXL104 in normal subjects and patients with varying degrees of renal insufficiency [abstract P1598]. 20th European Congress of Clinical Microbiology and Infectious Diseases; April 10-13, 2010; Vienna, Austria.

60. Levasseur P, Girard A, Coleman K. Optimal administration of ceftazidime (CAZ) plus avibactam (NXL104) for in vitro bacterial growth suppression of Enterobacteriaceae [abstract A-1688]. 51st Annual Interscience Conference on Antimicrobial Agents and Chemotherapy; September 10-17, 2011; Chicago, IL.

61. Noel AR, Tomaselli SG, Nicholls DL, Bowker KE, Williams G, MacGowan AP. The pharmacodynamics of avibactam (NXL104) in combination with either ceftaroline or ceftazidime against $\beta$-lactamase producing Enterobacteriaceae [abstract A-631]. 52nd Annual Interscience Conference on Antimicrobial Agents and Chemotherapy; September 9-12, 2012; San Francisco, CA.

62. Bowker KE, Noel AR, Macgowan AP. Pharmacodynamics of NXL104 plus either ceftaroline or ceftazidime against an AmpC producing Enterobacter spp. [abstract A2-556]. 51st Annual Interscience Conference on Antimicrobial Agents and Chemotherapy; September 17-20, 2011; Chicago, IL.

63. Merdjan H, Girard AM, Miossec C, Robertson M, Levasseur, P. Pharmacokinetics (PK) and efficacy of ceftazidime (CAZ)/NXL104 combination in a murine pneumonia model caused by an AmpC-producing Klebsiella pneumoniae [abstract A1-006]. 49th Annual Interscience Conference on Antimicrobial Agents and Chemotherapy; September 12-15, 2009; San Francisco, CA.

64. Levasseur P, Girard AM, Lavallade L, et al. Efficacy of ceftazidime/ NXL104 combination in murine septicemia caused by extendedspectrum $\beta$-lactamases and AmpC-producing Enterobacteriaceae sp. [abstract P1564]. 20th European Congress of Clinical Microbiology and Infectious Diseases; April 10-13, 2010; Vienna, Austria.

65. Endimiani A, Hujer KM, Hujer AM, Pulse ME, Weiss WJ, Bonomo RA. Evaluation of ceftazidime and NXL104 in two murine models of infection due to KPC-producing Klebsiella pneumoniae. Antimicrob Agents Chemother. 2011;55:82-85.

66. Cottagnoud P, Merdjan H, Acosta F, et al. Pharmacokinetics of the new $\beta$-lactamase inhibitor NXL104 in an experimental rabbit meningitis model: restoration of the bacteriological efficacy of ceftazidime (CAZ) against a class $\mathrm{C}$ producing $\mathrm{K}$. pneumoniae [abstract F1-321]. 47th Annual Interscience Conference on Antimicrobial Agents and Chemotherapy; September 17-20, 2007; Chicago, IL.

67. Borgonovi M, Miossec C, Lowther J. The efficacy of ceftazidime combined with NXL104, a novel $\beta$-lactamase inhibitor, in a mouse model of kidney infections induced by $\beta$-lactamase producing Enterobacteriaceae [abstract P794]. 17th European Congress of Clinical Microbiology and Infectious Diseases; March 31-April 3, 2007; Munich, Germany.

68. Vazquez JA, González Patzán LD, Stricklin D, et al. Efficacy and safety of ceftazidime-avibactam versus imipenem-cilastatin in the treatment of complicated urinary tract infections, including acute pyelonephritis, in hospitalized adults: results of a prospective, investigator-blinded, randomized study. Curr Med Res Opin. 2012;28:1921-1931.

69. Edeki T, Das S, Armstrong J, Mathews D. Effect of a supratherapeutic dose of ceftazidime on the QTc interval in a thorough QTc study [abstract P1417]. 22nd European Congress of Clinical Microbiology and Infectious Diseases; March 31-April 3, 2012; London, UK.

\section{Dovepress}

The manuscript management system is completely online and includes a very quick and fair peer-review system, which is all easy to use. Visit http://www.dovepress.com/testimonials.php to read real quotes from published authors. 